\title{
Uji Validitas dan Reliabilitas Konstruk Dukungan Sosial Menggunakan SEM
}

\author{
Chintia Amanda, Hadi Suyono, A.M. Diponegoro \\ Universitas Ahmad Dahlan, Yogyakarta \\ Email: chintiaamanda1992@gmail.com
}

\begin{abstract}
The purpose of this study is to test the validity and reliability of social support construction using SEM. The subjects of this study were 83 private high school students in Beringin Regency. The scale of this study uses a social support scale created by researchers developed from Smet (2004). The scale is arranged in the form of a Likert scale based on its aspects, totaling 24 statements with 4 answer choices. The scale was analyzed using SEM AMOS software version 24. The results of social studies provided to students helped improve the success of completing school.
\end{abstract}

Keywords: Social support, validity, reliability, SEM

\begin{abstract}
Abstrak
Tujuan penelitian ini adalah untuk menguji validitas dan reliabilitas konstruk dukungan sosial menggunakan SEM. Subjek penelitian ini adalah siswa SMA Swasta di Kecamatan Beringin yang berjumlah 83 siswa. Skala penelitian ini menggunakan skala dukungan sosial yang dibuat oleh peneliti mengembangkan dari Smet (2004). Skala disusun berupa skala Likert berdasarkan aspek-aspeknya yang berjumlah 24 pernyataan dengan 4 pilihan jawaban. Skala dianalisis menggunakan SEM software AMOS versi 24. Hasil penelitian menunjukkan bahwa dukungan sosial yang diberikan kepada siswa membantu meningkatkan keberhasilan menyelesaikan tugas sekolah.
\end{abstract}

Kata kunci: Dukungan sosial, validitas, reliabilitas, SEM

\section{Pendahuluan}

Dukungan sosial merupakan konstruk yang sangat penting untuk usia remaja saat ini. Dukungan sosial belakangan ini sering digunakan dalam banyak penelitian dibidang ilmu psikologi maupun pendidikan. Jindal-Snape (2010) menyoroti pentingnya dukungan sosial untuk meningkatkan prestasi siswa. Menurut Dollete, Steese, Phillips, \& Matthews (2004) dukungan sosial merupakan aspek yang perlu ditinjau lebih dalam karena dukungan sosial digambarkan sebagai penguat dan pemberi semangat kepada siswa. Demir (2019) mengatakan bahwa dukungan sosial memiliki efek positif pada kehidupan pribadi individu. Menurut Ozkalp dan Kirel (2010) bahwa dukungan sosial memberikan kebutuhan sosial dasar individu sebagai hasil dari interaksi individu dengan individu lain.

Demaray dkk (2005) mengkonseptualisasikan dukungan sosial sebagai dukungan yang diberikan orangtua, guru, teman sebaya, dan teman sekolah. Dukungan dari orangtua, guru, teman sebaya dan teman sekolah dipercaya mampu mengurangi masalah psikologis dikalangan siswa (Calvete \& Connor-Smith, 2006). Menurut Lakey \& Cohen (2000) kurangnya dukungan sosial yang diberikan lingukangan sekitarnya dapat membuat individu mudah stres dan mengakibatkan masalah psikologis pada siswa dan sebaliknya jika siswa mendapatkan dukungan sosial yang tinggi dari lingkungan sekitarnya maka masalah psikologi tidak akan muncul. Dukungan sosial penting diberikan pada individu agar individu terhindar dari masalah psikologis sehingga masalah dalam diri individu dapat dikendalikan. Hasil penelitian Asante (2011) menemukan bahwa dukungan sosial dapat membentuk kepribadian individu.

Menurut Yasin dan Dzukifli (2010) menjelaskan bahwa kurangnya dukungan sosial menjadi salah satu faktor yang menyebabkan banyaknya masalah psikologis siswa. Dukungan sosial yang tinggi memberikan penguatan pada kepribadian individu. Tao dkk (2000) yang mengatakan bahwa dukungan sosial berhubungan dengan kepribadian dan dukungan sosial dirasa perlu dalam membangun kepribadian individu. Tujuan dari penelitian ini adalah untuk menguji validitas dan reliabilitas konstruk dukungan sosial menggunakan SEM. 


\section{Dukungan Sosial}

Dukungan sosial merupakan pemberian bantuan fisik, emosional, informasi dan instrumental yang dirasakan individu dari lingkungannya (Lu dkk, 2015). Guney (2012) menjelaskan bahwa dukungan sosial merupakan komunikasi dengan kelompok dan individu lain. Dukungan sosial adalah suatu pemikiran sebagai suatu konstruk multidimensional yang terdiri dari komponen fungsional dan struktural. Dukungan sosial merujuk kepada tindakan yang orang lain lakukan ketika mereka menyampaikan bantuan (Roberts \& Gilbert, 2009). Hunt, Wilder dan Steele (2012) mengatakan bahwa dukungan sosial merupakan salah satu fungsi ikatan sosial dan ikatan-ikatan sosial tersebut menggambarkan tingkat kualitas umum dari hubungan interpersonal.

\section{Metode Penelitian}

\subsection{Responden}

Partisipan dalam penelitian ini adalah adalah siswa SMA Swasta kelas X sampai dengan kelas XII di Kecamatan Beringin. Jumlah responden dalam penelitian ini sebanyak 83 siswa.

\subsection{Pengumpulan Data}

Pengambilan data dilakukan pada tanggal 5 Desember 2019. Pengumpulan data dalam penelitian ini menggunakan skala. Skala dukungan sosial mengacu pada aspek-aspek dukungan sosial dari Smet (2004) antara lain dukungan emosional, dukungan penghargaan, dukungan instrumental dan dukungan informasi dengan jumlah 24 pernyataan.

\subsection{Teknik Analisis Data}

Teknik analisis data yang digunakan untuk membahas permasalahan dalam penelitian ini adalah Structural Equation Model (SEM). Model Persamaan Struktural atau Structural Equation Model (SEM) adalah teknik statistika yang memungkinkan pengujian suatu rangkaian hubungan yang relatif kompleks secara simultan (Ghozali, 2007). Kerangka konseptual dalam penelitian ini dapat dilihat pada gambar 1.

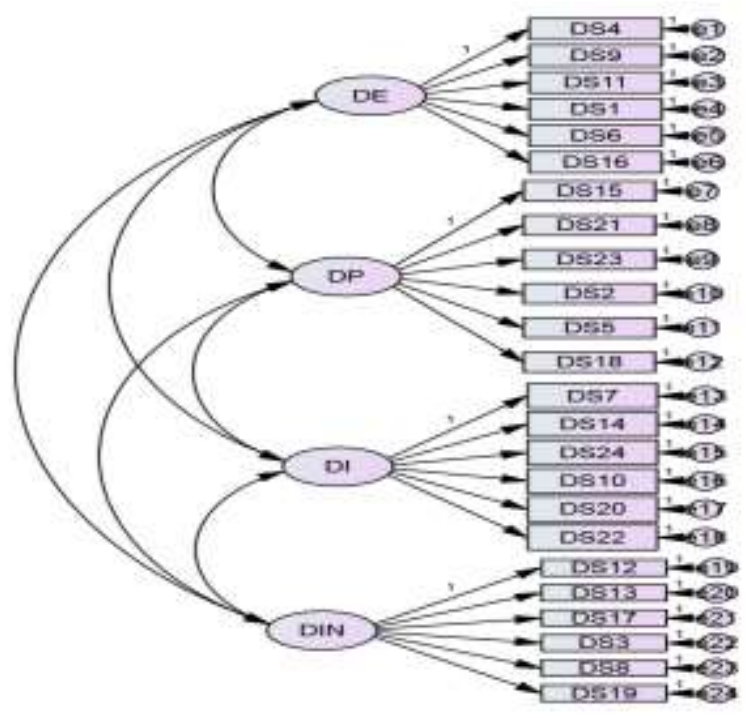

Gambar 1. Kerangka Konseptual

Keterangan:

DE : Dukungan Emosional

DP : Dukungan Penghargaan

DI : Dukungan Instrumental

DIN : Dukungan Informasi

DS : Dukungan Sosial 


\section{Hasil dan Pembahasan}

3.1. Validitas Konvergen

Uji validitas yang memenuhi nilai loading factor $>0,5$ maka dinyatakan valid. Berdasarkan hasil output skala hubungan dukungan sosial terdapat 15 item yang memiliki nilai loading factor $>0,5$ dinyatakan valid dan 15 item yang memiliki nilai loading factor $<0,5$ dinyatakan tidak valid.

Adapun output skala dukungan sosial dapat dilihat pada tabel 1 dan analisis hasil pengolahan data tahap pertama dengan melakukan uji validitas konvergen dapat dilihat pada gambar 2 .

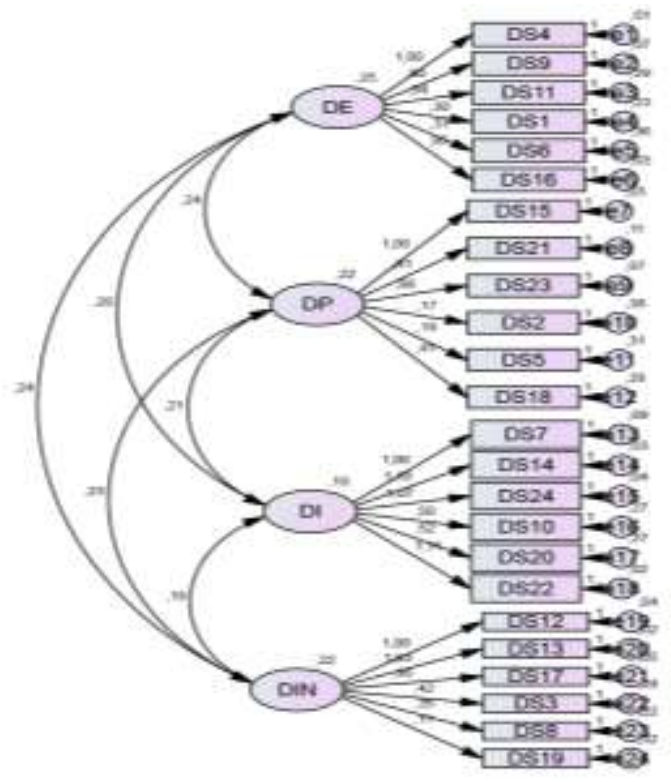

Gambar 2. Output Tahap pertama Uji Validitas Konvergen

\begin{tabular}{|c|c|c|c|}
\hline Aspek & Kode Aitem & Loading Factor & Keterangan \\
\hline \multirow{6}{*}{ Dukungan Emosional } & DS4 & 0.983 & Valid \\
\hline & DS9 & 0.438 & Tidak Valid \\
\hline & DS16 & 0.945 & Valid \\
\hline & DS1 & 0.299 & Tidak Valid \\
\hline & DS6 & 0.248 & Tidak Valid \\
\hline & DS11 & 0.295 & Tidak Valid \\
\hline \multirow{6}{*}{ Dukungan Penghargaan } & DS15 & 0.947 & Valid \\
\hline & DS21 & 0.454 & Tidak Valid \\
\hline & DS23 & 0.839 & Valid \\
\hline & DS2 & 0.129 & Tidak Valid \\
\hline & DS5 & 0.158 & Tidak Valid \\
\hline & DS18 & 0.340 & Tidak Valid \\
\hline \multirow{6}{*}{ Dukungan Instrumental } & DS7 & 0.217 & Tidak Valid \\
\hline & DS14 & 0.928 & Valid \\
\hline & DS24 & 0.501 & Tidak Valid \\
\hline & DS10 & 0.522 & Tidak Valid \\
\hline & DS20 & 0.395 & Tidak Valid \\
\hline & DS22 & 0.963 & Valid \\
\hline \multirow{5}{*}{ Dukungan Informasi } & DS12 & 0.926 & Valid \\
\hline & DS13 & 0.964 & Valid \\
\hline & DS17 & 0.497 & Tidak Valid \\
\hline & DS3 & 0.348 & Tidak Valid \\
\hline & DS8 & 0.329 & Tidak Valid \\
\hline
\end{tabular}

Psyche 165 Journal Terakredetasi Sinta 5 
Berdasarkan table 1. item yang tidak valid terdapat pada kode item DS1, DS6, DS9, DS11, DS21, DS2, DS5, DS18, DS7, DS24, DS10, DS20, DS17,DS3, DS8, DS19 maka item tersebut dinyatakan gugur. Berikut adalah gambar 2. estimasi ulang dan tabel 2. hasil estimasi ulang uji validitas skala dukungan sosial:

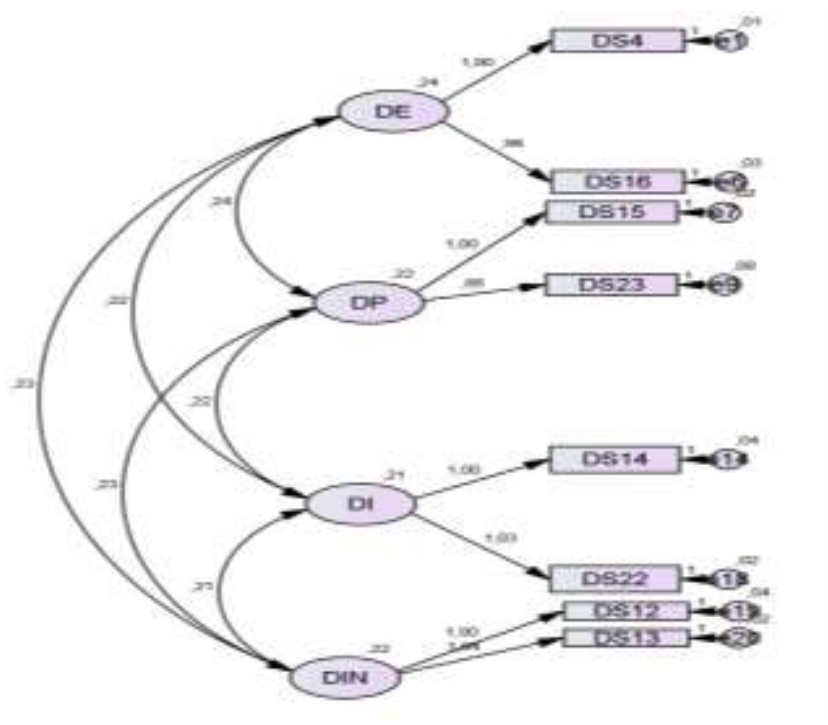

Gambar 3. Output Tahap Kedua Uji Validitas Konvergen

Tabel 2. Hasil Estimasi Ulang Uji Validitas Skala Dukungan Sosial

\begin{tabular}{cccc}
\hline \multirow{2}{*}{ Aspek } & Kode Aitem & Loading Factor & Keterangan \\
& DS4 & 0.979 & Valid \\
Dukungan Emosional & DS16 & 0.949 & Valid \\
& DS15 & 0.950 & Valid \\
Dukungan Penghargaan & DS23 & 0.821 & Valid \\
Dukungan Instrumental & DS22 & 0.966 & Valid \\
& DS14 & 0.911 & Valid \\
Dukungan Informasi & DS12 & 0.917 & Valid \\
& DS13 & 0.963 & Valid \\
\hline
\end{tabular}

Tabel diatas menunjukkan dukungan sosial memiliki validitas dengan nilai standardized factor loading yang berkisar antara 0,782 sampai dengan 0,979. Pada penelitian ini aitem yang valid berjumlah 8 penyataan.

\subsection{Reliabilitas}

Uji reliabilitas menunjukkan sejauh mana suatu alat ukur dapat memberikan hasil yang relatif sama apabila dilakukan pengukuran kembali pada objek yang sama. Menurut Ghozali (2017), nilai reliabilitas minimum yang dapat diterima adalah sebesar 0,70 . Koefisien reliabilitas konstruk dapat dihitung dengan rumus construct reliability, berikut ini disajikan perhitungan konstruk dukungan sosial.

Untuk menghitung Average Variance Extracted (AVE) dan Construct Reliability (CR) menggunakan rumus: 


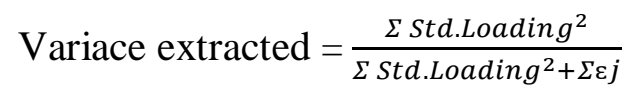

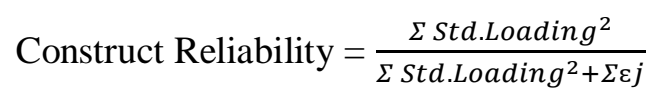

Hasil reliabilitas dapat dilihat pada tabel 3. berikut ini:

Tabel 3. Hasil Reliabilitas Dukungan Sosial

\begin{tabular}{cccc}
\hline Konstruk & AVE & CR & Keterangan \\
\hline Dukungan Sosial & 0.997 & 0.981 & Reliabel \\
\hline
\end{tabular}

Dari tabel 3 dapat diketahui juga bahwa dukungan sosial sudah memenuhi nilai reliabilitas minimum 0,70 dengan nilai AVE sebesar 0.997 dan CR sebesar 0,981. Dengan demikian maka dukungan sosial dianggap dapat memberikan hasil yang relatif sama apabila dilakukan pengukuran kembali pada objek yang sama. Hasil penelitian sebelumnya menunjukkan bahwa dukungan sosial membantu siswa menyelesaikan tugas-tugas sekolah (Sari \& Fakhruddiana, 2019). Hasil penelitian lainnya menurut Rosário, Costa, Núñez, González-Pienda, Solano, dan Valle (2009) menyebutkan bahwa dukungan sosial yang diberikan kepada siswa membantu meningkatkan keberhasilan dalam menyelesaikan tugas sekolah.

\section{Kesimpulan}

Berdasarkan pengumpulan dan pengolahan data serta analisis yang dilakukan, maka dapat diambil kesimpulan bahwa dari 24 pernyataan dukungan sosial hanya 8 pernyataan yang valid. Dapat disimpulkan bahwa dukungan sosial sangat penting bagi siswa SMA untuk menyelesaikan tugas sekolah. Siswa SMA di Beringin menyadari pentingnya dukungan sosial yang diberikan orang lain untuk mereka dalam keberhasilan menyelesaikan tugas-tugas sekolah. Pentingnya memberikan pemahaman kepada siswa selain dukungan sosial yang diberikan orang lain, diri mereka sendiri juga yang menentukan berhasil tidaknya dalam menyelesaikan tugas-tugas sekolahnya.

\section{Daftar Rujukan}

Calvete, H., \& Cornor-Smith, J.K. (2006). Perceived social support, coping, and symptoms of distress in American and Spanish students. Anxiety, Stress, and Coping, 19(1), $47-65$.

Demaray MK., Malecki, CK., \& Davison, L.M. (2005). The relationship between social support and student adjustment: a longitudinal analysis. Psychology in the Schools 42, 691-706.

Demir, S. (2019). A Structural Model on the Role of Perceived Multi-Dimensional Social Support in Attitudinal Variables. Ministry of Education, TURKEY, 607-616.

Dollete., Steese., Phillips., \& Matthews. (2004). Understanding girls' circle as an intervention on perceived social support, body image, self-efficacy, locus of control and self-esteem. The Journal of Psychology, 204-2015.

Guney, S. (2012). Orgutsel davranis [Organizational behaviour]. Ankara, Turkey: Nobel.

Hunt, C. W., Wilder. B., \& Steele, M. M.

Hunt, C. W., Wilder, B., \& Steele, M.M. (2012). Relationships among self-efficacy,social support, social problem solving, and self management in a rural sample living with type 2 diabetes mellitus. Research and Theory for Nursing Practice: An International Journal.

Jindal-Snape, D. (2010). Educational Transition-Moving stories from around the world . New York: Routledge.

Lakey, B., \& Cohen, S. (2000). Social support theory and measurement. New York: Oxford. 
Lu, M., Yang, G., Skora, E., Wang, G., Cai, Y., \& Sun Q.(2015). Self-esteem, social support, and life satisfaction in Chinese parents of children with autism spectrum disorder. Research in Autism Spectrum Disorders, 17, 70-77.

Ozkalp, E., \& Kirel, C. (2010). Orgutsel daranis (Organizational behavior). Bursa, Turkeey: Ekin.

P. Rosário, M. Costa, J.C Núñez, J. González-Pienda, P. Solano, and A. Valle, "Academic Procrastination: Associations with personal, School, and Family," The Spanish Journal of Psychology, vol. 12, no. 1, pp. 118 - 127, 2009.

Roberts, B.W., Luo, J., Briley, D. A., Chow, P.I., Su, R., \& Hill, P.L. (2017). “A systematic review of personality trait change through intervention", . Psychological Bulletin, Vol. 143 No. 2.

Sari, W.L., \& Fakhruddiana, F. (2019). Internal locus of control, social support and academic procrastination among students in completing the thesis. International Journal of Evaluation and Research in Education (IJERE), 8 (2), 363-368.

Smet, B. (2004). Psikologi Kesehatan. Jakarta: PT Grasindo.

Tao, S., Dong, Q., Pratt, M.W., Hunsberger, B., \& Pancer, S.M. (2000). Social support: Relations to coping and adjustment during the transition to university in the Peoples Republic of China. Journal of Adolescent Research, 5(1), 123-144.

Yasin, M.A.S.M., \& Dzulkifli, M.A. (2010). The Relationship between Social Support and Psychological Problems among Students. International Journal of Business and Social Science, Vol. 1 No. 3, 110-116. 